\title{
Canine cricopharyngeal achalasia: case report
}

\author{
[Acalasia cricofaríngea em cão: relato de caso] \\ C. Malm, E.M. Souza, P.E. Ferian, F.B. Fukushima, S.P. Macedo, O.H.R. Ladeira, \\ A.B.F. Faria, M.G.M.G. Andrade \\ Escola de Veterinária - UFMG \\ Caixa Postal 567 \\ 30123-970 - Belo Horizonte, MG
}

\begin{abstract}
A 7-month-old miniature poodle female dog was referred with dysphagia. After clinical, radiographic, and endoscopic examination, it was diagnosed a probable case of cricopharyngeal achalasia. The patient underwent surgical treatment and presented normal swallowing and no regurgitation after 24 hours postsurgery. Positive recovery and progressive body weight gain until 180 days after surgery was observed.
\end{abstract}

Keywords: dog, cricopharyngeal achalasia, dysphagia, regurgitation, surgery

\section{RESUMO}

Uma cadela da raça poodle miniatura com sete meses de idade foi atendida no Hospital Veterinário apresentando quadro de disfagia. Após exames clínico, radiográfico e endoscópico detalhados, houve diagnóstico provável de acalasia cricofaríngea. A paciente, submetida a tratamento cirúrgico, apresentou deglutição normal e nenhuma regurgitação 24 horas pós-cirurgia. Houve recuperação satisfatória e ganho de peso progressivo até 180 dias após a cirurgia.

Palavras-chave: cão, acalasia cricofaríngea, disfagia, regurgitação, cirurgia

\section{INTRODUCTION}

Cricopharyngeal achalasia (CPA) is an uncommon condition in dogs and other young animals (Ladlow and Hardie, 2000). CPA is a congenital functional abnormality stemming from the failure of the upper esophageal sphincter to open fully or in appropriate time, which leads to asynchrony between pharyngeal contractions and upper esophageal sphincter relaxations during swallowing (Sokolowsky, 1967; Rosin and Hanlon, 1972; Ladlow and Hardie, 2000; Pollard et al., 2000; Pfeifer, 2003; Pollard et al., 2007). Dogs affected with CPA have normal food prehension and passage of the bolus to the pharynx, but are unable to relax the upper esophageal muscles, particularly the cricopharyngeal muscle. Consequently, food remains in the caudal portion of the pharynx rather than proceeding into the esophagus,

Recebido em 19 de dezembro de 2009

Aceito em 22 de dezembro de 2010

E-mail: malm@vet.ufmg.br resulting in tracheal aspiration or regurgitation (Ladlow and Hardie, 2000; Pollard et al., 2000; Pfeifer, 2003). In humans, congenital cricopharyngeal achalasia (CCA) is a relatively rare condition with unknown etiology that also causes failure of the upper esophageal sphincter to relax during deglutition. The newborn displays dysphagia, choking, salivation, and nasal reflux upon feeding. This condition is primarily treated with either cricopharyngeal muscle myotomy or upper esophageal sphincter dilatation (Erdeve et al., 2007).

Dogs affected with CPA presented dysphagia, regurgitation immediately after an attempted swallowing event, coughing, excessive salivation, nasal reflux, insatiable appetite with poor growth, and aspiration pneumonia (Fossum, 1997; Ladlow and Hardie, 2000; Pollard et al., 2000; Pfeifer, 2003). Although there is no breed predisposition, CPA is usually associated with 
Cocker Spaniels, Cocker Springers, Miniature Poodles (Fossum, 1997), Foxhounds, Boxers, and mixed breeds (Sokolowsky, 1967; Weaver, 1983).

Accurate diagnosis of CPA requires a thorough clinical history including animal age at the onset of clinical signs, and disease progression, characterization of regurgitation, chewing and food prehension, ability to swallow liquids and solid foods, appetite, coughing, and nasal reflux (Rosin and Hanlon, 1972; Ladlow and Hardie, 2000).

Complementary exams, such as survey and contrast radiographs, endoscopy, and fluoroscopy, are important to diagnose CPA, determine the occurrence of concomitant aspiration pneumonia, exclude other diseases (foreign body esophageal obstruction, thoracic esophageal stenosis, and megaesophagus) and evaluate pharynx motility and passage of the food to the esophagus (Weaver, 1983; Fossum, 1997; Ladlow and Hardie, 2000).

Conventional treatments for CPA consist of transection (cricopharyngeal myotomy) or partial resection (cricopharyngeal myectomy) of the muscles that surround the upper esophagus, particularly the cricopharyngeal, the thyropharyngeal muscles or both (Baker, 1972; Slatter, 1993a; Fossum, 1997; Ladlow and Hardie, 2000; Pfeifer, 2003). After recovering from anesthesia, the canine patient may attempt swallowing small amounts of soft food, as swallowing usually improves immediately after surgery (Sokolowsky, 1967; Rosin and Hanlon, 1972; Weaver, 1983; Fossum, 1997; Ladlow and Hardie, 2000).

The objective of this work was to report a case of cricopharyngeal achalasia in a female Poodle exhibiting signs of dysphagia.

\section{CASE REPORT}

A 7-month-old Miniature Poodle bitch presented a history of dysphagia since weaning. She presented normal appetite but displayed intense anxiety while feeding, excessive chewing with frustrating attempts to swallow, and episodes of choking and regurgitation. Only after repeated attempts to swallow, part of the bolus passed into the esophagus. Although it was easier to swallow liquids and soft foods, the Poodle was unable to adequately intake appreciable amounts of solid food. Additionally, the owner reported major difficulties to nurse, nasal reflux with milk, body underdevelopment, and low weight gain since weaning. The patient had already experienced repeated episodes of bacterial pneumonia that had been treated with various antibiotics. Treatments with prednisone and cisapride did not lead to any clinical improvement of dysphagia, as no definitive diagnosis had been given at that time.

Upon examination, the animal weighed $2.65 \mathrm{~kg}$ with a body score of 2 (using the Nestlé-Purina body condition evaluation system), which indicated underfeeding. The patient exhibited noisy lung auscultation, but appeared alert with normal heart and respiratory rates and body temperature. Initial diagnosis was megaesophagus and aspiration pneumonia.

Survey radiographs did not reveal any abnormal lung pattern or esophageal dilatation. Contrast esophageal radiography revealed barium sulfate aspiration through the larynx and respiratory tract, strongly suggesting a disruption of pharyngeal swallowing phase.

Endoscopic evaluation with a rigid endoscope (Rigid Endoscope Hopkins KARL-STORZ ${ }^{\circledR}$ $\mathrm{GmbH}$ and Co.) allowed visibilization of the larynx, tonsils, epiglottis, oropharynx, and distal trachea. No anatomical or obstructive abnormalities were observed, and laryngeal movements appeared normal. However, a large amount of spumous laryngeal-tracheal secretion and hyperemic and irregular tracheal mucosa were observed.

Clinical and complementary examinations, in addition to the history of the animal, revealed the possibility of a rare case of cricopharyngeal achalasia. Results of hematological and biochemical exams were normal. The 9-monthold animal was surgically treated.

The animal was submitted to an 8-hour water and food fast during the preoperative period. It was administered sodic cefalotin (30mg/kg/IV) with two additional doses in 8-hour intervals. Preanesthetic medication was a combination of acepromazin $(0.05 \mathrm{mg} / \mathrm{kg} / \mathrm{IM})$ and petidin chloride (3mg/kg/IM). Anesthesia was inducted 
with propofol $(5 \mathrm{mg} / \mathrm{kg} / \mathrm{IV})$ and maintained with isofluorane. The animal was positioned in dorsal recumbency, and the surgical field was prepared by clipping the hair and scrubbing the area with povidone-iodine and iodine tincture. An approximately $7 \mathrm{~cm}$ in length ventral incision was made, beginning cranial to the larynx and extending caudally to the mid-cervical area to expose the sternohyoid muscle and to incise its mid-portion. Thus, it was possible to visualize and lateralize the trachea, partially rotate the larynx and the trachea, and allow exposure and identification of the cricopharyngeal, thyropharyngeal, and hyopharyngeal muscles, which had normal aspect (Figure 1). The laryngeal recurrent nerve was isolated to prevent injury and placed lateral to the trachea. A tube was introduced into the esophagus to aid in identification of the esophageal wall. A partial longitudinal myectomy was performed on a segment of the cricopharyngeal and thyropharyngeal muscles approximately one centimeter long with a width of $0.5 \mathrm{~cm}$ (Figure 2), leaving the hyopharyngeal muscle uninjured. Extra care was taken to prevent perforation of the esophageal wall and, at last, the esophagus was inspected for possible lesions. The sternohyoid muscle was sutured in a simple continuous pattern with poliglecaprone 4-0 (Caprofyl $^{\circledR}$ Johnson and Johnson). Finally, the subcutaneous tissue was sutured as previously, and dermorraphy proceeded in a simple interrupted pattern with a polyamide 3-0 (Nylon ${ }^{\circledR}$ - Johnson and Johnson). Muscular fragments were histologically evaluated and revealed the presence of focal neutrophylic myositis and discrete muscular atrophy.

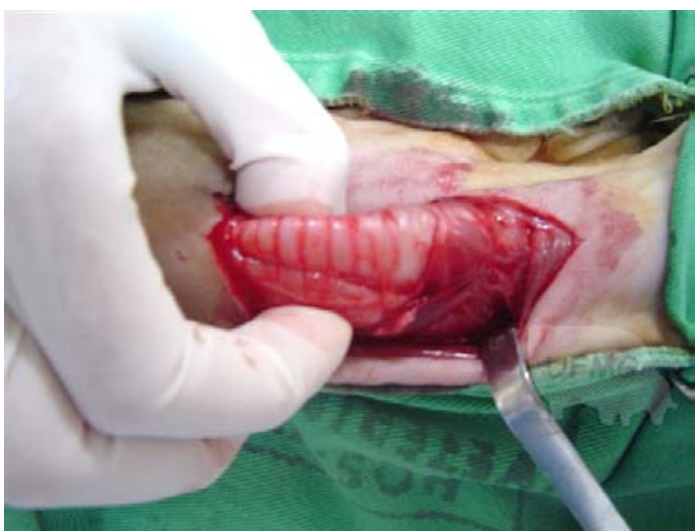

Figure 1. Exposition and lateralization of the trachea with exposure of the cricopharyngeal, thyropharyngeal, and hyopharyngeal muscles.

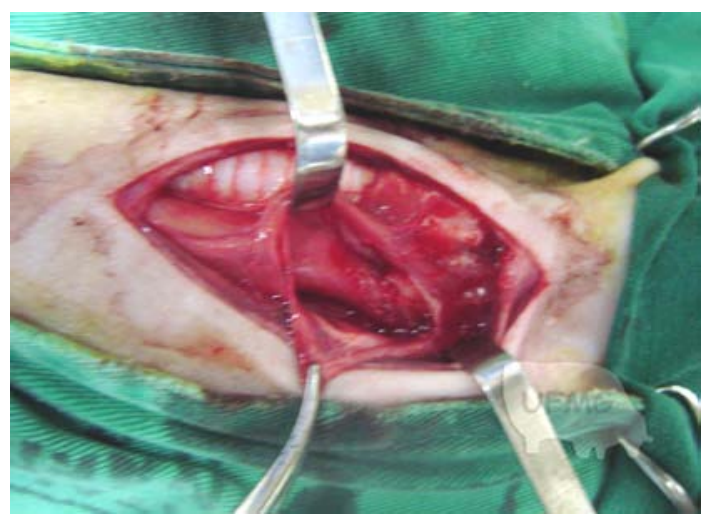

Figure 2. Partial longitudinal myectomy on cricopharyngeal and thyropharyngeal muscles.

Dexamethasone $\quad(0.8 \mathrm{mg} / \mathrm{kg} / \mathrm{IV} \quad$ and $0.8 \mathrm{mg} / \mathrm{kg} / \mathrm{SID} / 2$ days), tramadol chloride (2mg/kg/IM and 2mg/kg/IM/TID/3 days), and lincomicine chloride (10mg/kg/IM/BID/10 days) were postoperatively administered. The patient remained at the Veterinary Hospital during the first 48 hours for clinical observation, pain management, and evaluation of initial solid and liquid food intake. Humid food (Canine i/d Prescription Diet - Hill's) was offered and normal swallowing without regurgitation was observed 24 hour post-surgery. The animal was discharged from hospital 48 hours after surgery, and the owner was directed to offer small amounts of soft food several times a day and gradually change to solid foods. On post-surgery day $10^{\text {th }}$, external sutures were removed on, normal healing of the surgical wound was observed. There was significant improvement in body condition with $500 \mathrm{~g}$ of weight gain and normalization of feeding behavior. The canine patient was able to swallow water and soft foods. The owner reported normal swallowing of liquids and solid foods, no regurgitation or anxiety during feeding and body weight gains of $3.2 \mathrm{~kg}$ (18\% increase) and $3.45 \mathrm{~kg}$ (23\% increase) after 45 and 180 days of surgery, respectively.

\section{DISCUSSION}

Cricopharyngeal achalasia is a rare type of oropharyngeal dysphagia characterized by the inability to pass the bolus into the cervical esophagus from failure to open the upper esophageal sphincter (Baker, 1972). Here, it was reported a female Poodle with excessive chewing, repeated attempts to swallow, choking, regurgitation, and anxiety during the feeding 
period since weaning. Additionally, the animal presented difficulty in swallowing and milk nasal reflux during the nursing phase, resulting in an insufficient body weight of $800 \mathrm{~g}$ at 70 days of age. Although most dogs appear normal until starting solid food intake, clinical symptomatology was similar to that described by others (Fossum, 1997; Ladlow and Hardie, 2000; Pfeifer, 2003) who also observed these static symptoms during nursing unless complicated by pneumonia (Ladlow and Hardie, 2000).

Animals with dysphagia upon physical examination exhibit active behavior and are usually thinner and smaller than normal for their age group (Fossum, 1997; Ladlow and Hardie, 2000). Differentiating the various causes of dysphagia requires a thorough oral examination and observation of the animal during eating and drinking to determine if the problem is oral or pharyngeal (Sokolowsky, 1967; Fossum, 1997; Pfeifer, 2003; Ladlow and Hardie, 2000). The bitch displayed signs of dysphagia with normal food prehension that excluded the oral type. However, the animal exhibited difficulty and delays in swallowing solid foods, although swallowing liquids appeared easier. Patients with oral dysphagia present difficulties in prehension and formation of the bolus (Sokolowsky, 1967; Fossum, 1997; Ladlow and Hardie, 2000; Pollard et al., 2000; Pfeifer, 2003; Pollard et al., 2007), while those with pharyngeal dysphagia have difficulty in passing the bolus into the esophagus in addition to other signs such as gagging and repeated swallowing attempts. Cricopharyngeal dysphagia is associated with abnormal passage of the bolus through the partially opened upper esophageal sphincter. Although oral and pharyngeal dysphagia exhibit similar symptoms, patients with cricopharyngeal dysphagia usually present more difficulties with solid food intake, while those with other types of dyphagia have more difficulty with swallowing liquids. The attempts to swallow may result in coughing, choking, and aspiration pneumonia. The animal experienced various episodes of aspiration pneumonia during the first four months of clinical treatment.

Thoracic radiographs are important to diagnose aspiration pneumonia. Simple and contrast radiographs can exclude esophageal obstruction by a foreign body, thoracic esophagus stenosis, and megaesophagus (Weaver, 1983), as occurred in the present case. The majority of the contrast material was aspirated, which suggested pharyngeal dysphagia (Slatter, 1993a; Pollard et al., 2007). Endoscopic examination was important to excluded aspiration caused by other morphological abnormalities of the pharynx and larynx and it revealed macroscopic characteristics of tracheal inflammation such as hyperemia and secretion. The history of the animal and thorough clinical examinations conducted here provided sufficient information to diagnose CPA, which allowed for surgical intervention and therapeutic treatment.

Ventral midline cervical incision with the dog in dorsal recumbency is performed in majority of surgeries. The pharynx and trachea are rotated to expose the dorsal cricopharyngeal muscle and avoid damage to both the recurrent laryngeal nerve and esophageal wall. Introduction of a gastric tube aids in the identification of muscular fibers of the upper esophageal sphincter (Sokolowsky, 1967; Ladlow and Hardie, 2000; Pfeifer, 2003). In most cases, transection of cricopharyngeal muscle instead of removal of the muscle is sufficient to fix CPA, but all the fibers of the cricopharyngeal muscle must be transected in order to avoid dysphagia recurrence (Rosin and Hanlon, 1972; Weaver, 1983; Slatter, 1993b; Ladlow and Hardie, 2000). Another option is to transect a portion of the thyropharyngeal muscle. In the present case, the cricopharyngeal, thyropharyngeal, and hyopharyngeal muscles were identified, and partial myectomy of the cricopharyngeal and thyropharyngeal muscles was performed to minimize recurrence of dysphagia due to fibrosis and constriction (Niles et al., 2001; Pfeifer, 2003; Warnock et al., 2003).

Alternatively, the animal can be placed in right lateral recumbency for surgical incision on the left dorsal side of the larynx and ventral to the jugular vein, beginning at the rostral aspect of the cricoid cartilage (Pfeifer, 2003). A portion of the cricopharyngeal muscle is then identified, elevated, and resectioned. This approach is described as easier to perform technically and allows faster identification of the cricopharyngeal muscle.

Previous studies suggest that the cause of CPA may be cricopharyngeal hypertrophy or myositis (Sokolowsky, 1967; Weaver, 1983). Based on three cases reported, myositis and subsequent 
atrophy can lead to physical incapability of the upper esophagus (Pearson, 1970). Here, histological results from muscular fragments indicated focal neutrophilical myositis and discrete muscular atrophy. In other two cases, hypertrophy, chronic myositis, or fibrosis was not detected (Weaver, 1983).

Postoperative care consisted of keeping the animal quiet without sedation, providing analgesia after anesthetic recovery. Swallowing can be evaluated by offering a small amount of soft food (Sokolowsky, 1967; Rosin and Hanlon, 1972; Weaver, 1983; Ladlow and Hardie, 2000). Food intake is recommended one day after surgery to keep adequate dilation of the upper esophagus. The evident improvement in swallowing is expected immediately after the operation and is usually progressive (Fossum, 1997; Ladlow and Hardie, 2000). In this case, the response of the animal to food 24 hours postsurgery was considered satisfactory, as normal swallowing of humid food was observed. Administration of opioid, antibiotic, and dexamethasone during the postoperative period was carried out as recommended (Pfeifer, 2003).

Postoperative complications include fibrosis and constriction at the site of myotomy or myectomy, recurrent laryngeal paralysis, esophageal perforation, dysphagia recurrence, pharyngocutaneous fistula, seroma, and surgical wound infection (Ladlow and Hardie, 2000; Pfeifer, 2003). The recurrence of dysphagia due to fibrosis and constriction can be prevented by complete resection of all muscular fibers (Ladlow and Hardie, 2000; Pfeifer, 2003; Warnock et al., 2003). In the present report, these cited intercurrences and complications did not occur. Six months after surgery, the animal presented normal behavior during intake of liquids, soft, and solid foods with a weight gain of $23 \%$ compared to the first consult. By 14 months of age, the animal exhibited active and alert behavior.

The prognosis after surgical intervention is favorable if only CPA is presented. In spite of complete recovery is expected, some animals exhibited only partial improvement while others demonstrated recurrence of clinical signs and persistent regurgitation within 2 to 36 weeks (Slatter, 1993a; Warnock et al., 2003). The prognosis without surgical treatment is guarded due to the difficulty in effectively nourishing and controlling aspiration pneumonia in these animals (Fossum, 1997). Surgery is not recommended for dogs with CPA complicated by other anatomical or functional abnormalities such as myasthenia gravis, laryngeal paralysis, and esophageal stenosis (Warnock et al., 2003).

\section{REFERENCES}

BAKER, G.J. Surgery of the canine pharynx and larynx. J. Small Anim. Pract., v.13, p.505-513, 1972.

ERDEVE, O.; KOLOGLU, M.; SAYGILI, B. et al. Primary cricopharyngeal achalasia in a newborn treated by balloon dilatation: a case report and review of literature. Int. J. Pediatr. Otorhinolaryngol., v.71, p.165-168, 2007.

FOSSUM, T.W. Small animal surgery. 1.ed. Philadelphia: Mosby Elsevier, 1997. p.255-258.

LADLOW, J.; HARDIE, R.J. Cricopharyngeal achalasia in dogs. Compend. Contin. Educ. Pract. Vet., v.22, p.750-755, 2000

NILES, J.D.; WILLIAMS, J.M.; SULLIVAN, M. et al. Resolution of dysphagia following cricopharyngeal myectomy in six young dogs. J. Small Anim. Pract., v.42, p.32-35, 2001.

PEARSON, H. The differential diagnosis of vomiting in the young dog. J. Small Anim. Pract., v.11, p.403-415, 1970

PFEIFER, R.M. Cricopharyngeal achalasia in a dog. Can. Vet. J., v.44, p.993-995, 2003.

POLLARD, R.E.; MARKS, S.L.; DAVIDSON, A. et al. Quantitative videofluoroscopic evaluation of pharyngeal function in the dog. Vet. Radiol. Ultrasound., v.41, p.409412, 2000 .

POLLARD, R.E.; MARKS, S.L.; LEONARD, R. et al. Preliminary evaluation of the pharyngeal constriction ratio (PCR) for fluoroscopic determination of pharyngeal constriction in dysphagic dogs. Vet. Radiol. Ultrasound., v.48, p.221-226, 2007.

ROSIN, E.; HANLON, G.F. Canine cricopharyngeal achalasia. J. Am. Vet. Med. Assoc., v.160, p.1496-1499, 1972.

SLATTER, D. Textbook of small animal surgery. 2.ed. Philadelphia: Saunders, 1993a. p.530-534.

SLATTER, D. Textbook of Small Animal Surgery. 2.ed. Philadelphia: Saunders, 1993b. p. 549-561.

SOKOLOWSKY, V. Cricopharyngeal achalasia in a dog. $J$. Am. Vet. Med. Assoc., v.150, p.281-284, 1967.

WARNOCK, J.J.; MARKS, S.L.; POLLARD, R. et al. Surgical management of cricopharyngeal dysphagia in dogs: 14 cases $(1989$ - 2001). J. Am. Vet. Med. Assoc., v.15, p.1462-1468, 2003.

WEAVER, A.D. Cricopharyngeal achalasia in Cocker Spaniels. J. Small Anim. Pract. v.24, p.209-214, 1983. 